Received Date : 04-Nov-2016

Revised Date : 22-Dec-2016

Accepted Date : 27-Dec-2016

Article type : Brief Report

\title{
Valproate Protein Binding is Highly Variable in I CU Patients and Not Predicted by Total Serum Concentrations: A Case Series and Literature Review
}

Richard R. Riker, MD ${ }^{1,2}$; David J. Gagnon, PharmD³; Colman Hatton, MD4; Teresa May, DO ${ }^{1,2}$; David B. Seder, MD ${ }^{1,2}$; Katie Stokem, DO ${ }^{1,2}$; Gilles L. Fraser, PharmD ${ }^{1,3}$

${ }^{1}$ Critical Care Medicine, Maine Medical Center, 22 Bramhall Street, Portland, ME USA

${ }^{2}$ Neurocritical Care and Neuroscience Institute, Maine Medical Center, 22 Bramhall Street, Portland, ME USA

${ }^{3}$ Department of Pharmacy, Maine Medical Center, 22 Bramhall Street, Portland, ME USA

${ }^{4}$ Department of Emergency Medicine, University of Michigan School of Medicine, Ann Arbor, MI USA

Corresponding Author: Richard R. Riker, MD, Director of Medical Critical Care, Maine Medical Center, 22 Bramhall Street, Portland, Maine 04102, USA. Email: rriker@cmamaine.com, phone 207-6622179, fax 207-662-6326

Keywords: valproate; valproic acid; divalproex; adverse drug effects; myoclonus; protein binding; therapeutic drug monitoring; seizure; intensive care

Presented in part at the 6th International Hypothermia and Temperature Management Symposium, Philadelphia, PA September 12-14, 2016 (4 patients) and the $46^{\text {th }}$ Critical Care Congress of the Society of Critical Care Medicine, Honolulu, HI January 21-25, 2017 (11 patients) 
Word Count: 2717 words

Abstract: 290 words

Running Head: Valproate Binding ICU Highly Variable

\section{Abstract}

Study Objective: The free fraction of valproate (the pharmacologically active moiety, normally 5$10 \%$ ) may vary significantly in critically ill patients, but this topic is understudied, with only 4 prior ICU case reports. The objective of this study was to evaluate the range of valproate plasma protein binding in ICU patients.

Design: Observational study of consecutive ICU patients

Setting: Neurocritical and medical critical care services in a non-university academic medical center

Patients: Consecutive ICU patients treated with valproate with serum albumin $<4 \mathrm{~g} / \mathrm{dL}$

Measurements and Main Results: Simultaneous total and free trough serum valproate concentrations were measured as were serum creatinine, blood urea nitrogen BUN, albumin, platelets, and transaminase values. The reference concentration range was 50-125 mg/L (total) and 5-17 mg/L (free). Valproate concentrations were categorized as within reference range, low, or high, and as concordant if both concentrations were in the same category. Data are reported as median (interquartile range). Fifteen patients ( 9 males) were evaluated. The median age was 63 (34-70) years. The valproate dose was $3 \mathrm{~g} /$ day $(35 \mathrm{mg} / \mathrm{kg} /$ day). No patient had a valproate free fraction of $5-$ $10 \%$; the median was $48 \%$, and the range was $15-89 \%$. Total and free concentrations showed poor correlation (0.43) and were concordant in only 2 patients (both in reference range). Free valproate was poorly predicted by an equation correcting for albumin $(r=0.45)$. Suspected adverse drug events occurred in 10 patients: hyperammonemia in $7 / 12$ tested (58\%), elevated transaminases in 2/15 (13\%), and thrombocytopenia in 5/15 (33\%).

Conclusions: Protein binding of valproate is highly inconsistent in this cohort of ICU patients, and total valproate concentrations did not predict free concentrations, even when correcting for albumin. Additional research to define best practice for dosing and monitoring valproate and the relationship between free valproate concentrations and clinical or adverse effects in ICU patients is needed. Introduction

Valproate is an antiepileptic and mood stabilizing agent approved by the Food and Drug This article is protected by copyright. All rights reserved 
Administration in 1979. Doses are typically adjusted to a total serum valproate concentration of 50$100 \mathrm{mg} / \mathrm{L}$ when treating seizures and $50-125 \mathrm{mg} / \mathrm{L}$ for behavioral disorders. ${ }^{1,2}$ Valproate is highly protein bound to albumin ( $\geq 90 \%$ ), and the pharmacologically active unbound or free fraction is typically $5-10 \%$ of the total valproate concentration, but may vary significantly. ${ }^{3}$ Valproate protein binding has been understudied, as we are aware of only 4 reported cases of free valproate monitoring in ICU patients. ${ }^{4-7}$ Reviews and guidelines recommend monitoring serum valproate concentrations, but make sparse or no mention of free serum concentration monitoring or altered protein binding. ${ }^{8}$

Our interest in monitoring free serum valproate concentrations began after treating a patient with decreasing total serum valproate concentrations despite increasing doses, with several adverse drug events. The free fraction and free serum valproate concentrations were elevated despite a low total concentration less than $30 \mathrm{mg} / \mathrm{L}$. The primary objective of this study was to evaluate the frequency and extent of deranged valproate plasma protein binding in a cohort of consecutive critically ill patients. The secondary objectives were to assess the capability of a previously published equation to predict free serum valproate concentrations from albumin and total valproate concentrations. ${ }^{13,14}$

\section{Materials and Methods}

Index Case

A 72-year-old man weighing $103 \mathrm{~kg}$ remained comatose after in-hospital cardiac arrest. Targeted temperature management was initiated at $33^{\circ} \mathrm{C}$ for 24 hours, with controlled rewarming over 12 hours. On hospital day (HD) 3, he developed intermittent myoclonus with generalized polyspike and wave discharges of high amplitude on electroencephalography that persisted despite levetiracetam and continuous midazolam therapy. Because neuron-specific enolase testing and magnetic resonance imaging on HD4 did not identify severe brain injury, aggressive care was continued. Valproate (30 $\mathrm{mg} / \mathrm{kg} /$ day) and a propofol infusion were added on HD4. On HD7, the total serum valproate concentration was $71 \mathrm{mg} / \mathrm{L}$ (reference range $50-100 \mathrm{mg} / \mathrm{L}$ ), but a repeat total concentration on HD12 was low (31 mg/L) despite no change in valproate dose (Figure 1). A 2000-mg dose of valproate was administered, and the maintenance dose increased to $40 \mathrm{mg} / \mathrm{kg} /$ day. On HD13, the total concentration was $30 \mathrm{mg} / \mathrm{L}$, again prompting a valproate bolus and increase in the maintenance This article is protected by copyright. All rights reserved 
regimen to $60 \mathrm{mg} / \mathrm{kg} /$ day. On HD14, the total concentration was lower at $26 \mathrm{mg} / \mathrm{L}$, and the dose increased again to $80 \mathrm{mg} / \mathrm{kg} /$ day. Serum for total and free valproate concentration measurement was sent to a reference lab, which returned on HD16, revealing an even lower total concentration [22 $\mathrm{mg} / \mathrm{L}$ ), an elevated free concentration of $19 \mathrm{mg} / \mathrm{L}$ (reference range 5-17 $\mathrm{mg} / \mathrm{L}$ ), and a dramatically elevated free fraction of $86 \%$. Coupled with an elevated ammonia concentration (135 $\mu \mathrm{mol} / \mathrm{L})$ and worsening transaminases, valproate therapy was discontinued. After repeated failures to control epileptiform discharges, the family requested withdrawal of life-sustaining therapy.

Study Design

Maine Medical Center (MMC) is an academic medical center with 58 adult ICU beds. We prospectively monitored consecutive adult patients admitted to the neurocritical or medical critical care services from September 2015 through August 2016 who were treated with valproate with serum albumin concentrations $<4.0 \mathrm{~g} / \mathrm{dL}$. When the bedside treatment team ordered valproate concentrations, simultaneous total and free serum valproate concentrations were obtained. Total and free valproate assays were sent to a reference lab [Mayo Clinic Medical Laboratories, Rochester, MN) with a delay of several days. Total serum valproate and free serum valproate concentrations were determined via enzyme immunoassay using the Roche Cobas 8000 system. Free serum valproate was measured after ultrafiltration with the Millipore Centrifree micropartition system (EMD Millipore, Billerica, MA). In response to the index case, this study was designed as a Quality Improvement pilot project with approval by our IRB.

We collected patient demographic data including age, gender, weight, reason for ICU admission, length of stay, serum albumin, blood urea nitrogen, and creatinine concentration on the day simultaneous free and total serum concentrations were measured. If more than one free valproate concentration was obtained, the sample with the highest free fraction was used.

Drug administration data were collected from the electronic Medication Administration Record, including the dose ( $\mathrm{g} /$ day and $\mathrm{mg} / \mathrm{kg} /$ day) on the day the serum concentrations were obtained, indication for valproate therapy, whether valproate was started during this ICU admission, and time from valproate initiation to measurement of serum concentrations. Concomitant administration of aspirin, propofol, and/or Intralipid® was recorded. Inappropriate dose escalation was defined as an increase in valproate dose based on total serum valproate concentration, when the free concentration This article is protected by copyright. All rights reserved 
suggested the dose should not have been increased.

Outcomes and Statistical Analysis

We assessed possible valproate-induced adverse effects during valproate administration until hospital discharge. Only patients who had baseline laboratory values prior to valproate initiation were assessed for laboratory-based adverse effects. Hepatotoxicity was defined as a new alanine aminotransferase (ALT) $>3$ times the upper limit of normal (ULN) $(>120 \mathrm{U} / \mathrm{L})$, alkaline phosphatase $>2$ times the ULN (>234 U/L), total bilirubin $>2$ times the ULN (>2 mg/dL), or a doubling of the baseline value for ALT, alkaline phosphatase, or bilirubin if abnormal prior to valproate initiation. ${ }^{15}$ Thrombocytopenia was defined as a platelet count $<140,000$ cells $/ \mathrm{mm}^{3}$ or reduction in platelet count by $>50 \%$ if platelets were already $<140,000$ cells $/ \mathrm{mm}^{3}$ following valproate initiation. ${ }^{16}$ Hyperammonemia was defined as a new serum ammonia level $\geq 60 \mathrm{umol} / \mathrm{L}$ following valproate initiation.

We compared the measured free serum valproate concentration to a predicted free serum concentration derived from the equation published by Parent et al: free fraction $(\%)=A e^{-B X}$, where $X$ corresponds to albumin concentration ( $\mathrm{mmol} / \mathrm{L}$ ), with constants $A=130.69$ and $B=4.96 \times 10^{-3} .{ }^{13,14}$ The total, free, and predicted free serum valproate concentrations were compared using the Spearman correlation, and the bias between mean differences was assessed with Altman-Bland analysis by Analyse-it ${ }^{\circledR}$ software. ${ }^{17}$ Concentrations were categorized relative to the reference ranges for total (50-125 mg/L) and free (5-17 mg/L) serum valproate concentration as in the reference range or below ("low") or above the reference range ("high"). If both total and free concentrations were in the same category, we considered them therapeutically concordant. If the concentrations were in different categories, they were considered therapeutically discordant. Data are presented as median (interquartile range or IQR) with $p<0.05$ considered significant.

\section{Results}

From September 2015 through August 2016, 15 medical or neurological critical care patients were monitored (including the Index Case). The subjects were mostly male with a wide distribution of ages (Table 1). Valproate was administered for seizures $(n=6)$, myoclonus $(n=4)$, bipolar disorder $(n=3)$, schizophrenia $(n=1)$, or refractory agitated behavior $(n=1)$. Three patients $(20 \%)$ were This article is protected by copyright. All rights reserved 
receiving valproate at the time of $I C U$ admission at the same dose used prior to hospitalization

The total serum valproate concentration was $52 \mathrm{mg} / \mathrm{L}$ (IQR, 29-65 mg/L) with a range of 22$92 \mathrm{mg} / \mathrm{L}$, representing low or reference range values only. No patient had a valproate free fraction of 5-10\%; the median unbound or free valproate fraction was $48 \%$ (IQR, 39-56\%; range, $15-89 \%$ ). Despite the low or reference range total valproate levels, the increased free fraction was associated with free serum valproate concentrations that were often above the reference range at 20 (IQR 1830) $\mathrm{mg} / \mathrm{L}$ (range, $11-37 \mathrm{mg} / \mathrm{L}$ ). The median valproate dose was $3.0 \mathrm{~g} /$ day (IQR, $2.0-4.0 \mathrm{~g} / \mathrm{day}$ ) or $35 \mathrm{mg} / \mathrm{kg} /$ day (IQR, $27-43 \mathrm{mg} / \mathrm{kg} /$ day). On the day valproate concentrations were drawn (drug day 4 [IQR 3-11], the median albumin value was $2.4 \mathrm{~g} / \mathrm{dL}$ (IQR, 2.2-3.0 g/dL), blood urea nitrogen was $21 \mathrm{mg} / \mathrm{dL}$ (IQR, $15-28 \mathrm{mg} / \mathrm{dL}) \mathrm{mg} / \mathrm{dL}$, and serum creatinine was $0.87 \mathrm{mg} / \mathrm{dL}$ (IQR, 0.56-1.2 mg/dL). Eight patients (53\%) were receiving medications known to alter valproate protein binding; propofol infusions ( $n=5)$, aspirin $(n=2)$, and both propofol and aspirin $(n=1)$ (Table 2). The median time from drawing the serum sample to valproate concentration availability was 3 days (range, 2-4 days).

The total serum valproate concentration was low in $6(40 \%)$ patients, and in reference range in $9(60 \%)$ patients (Figure 2). The free valproate concentration was never low, but was high in 12 $(80 \%)$ patients and in reference range in $3(20 \%)$ patients. Total and free concentrations were concordant in only 2 patients (13\%). Among the 6 patients with low total concentrations, which would likely have resulted in valproate dose increases based on the total concentration, free concentrations were high in 5 (83\%).

The correlation was poor between total and free serum valproate concentration $(r=0.43)$, between measured and predicted free serum valproate concentration $(r=0.45)$ (Figure 3), and between albumin and free fraction $(r=0.21)$. When the bias between measured and estimated free serum valproate concentrations using the Parent formula was compared using Altman-Bland techniques (eFigure 1), the Parent formula consistently underestimated free concentrations with a bias of $-11.9 \mathrm{mg} / \mathrm{L}$, and $95 \%$ Limits of Agreement of -28 to 4.2 .

Adverse drug events possibly associated with valproate therapy occurred in 10 patients (68\%) (Figure 2). Seven of 12 patients tested (58\%) had hyperammonemia, 2/15 (13\%) developed 
elevated transaminases, and 5/15 (33\%) had thrombocytopenia. Unexpectedly, four of the five patients without adverse drug events had among the highest free concentrations we recorded. The first 2 patients monitored received inappropriate dose adjustments based on total serum valproate concentrations. Learning from those events, providers checked free serum valproate concentrations earlier, and none of the next 13 patients received dose supplements inappropriately.

\section{Discussion}

No patient in our consecutive series had a normal free fraction of valproate of $5-10 \%$, instead concentrations ranged from $15-89 \%$. Monitoring total concentrations of medications is based on the assumption that they reflect free concentrations (i.e. that the free fraction is predictable and is consistent between patients) $;{ }^{18}$ clearly this is not the case for valproate among our cohort of ICU patients. Total serum valproate concentrations were usually low or in the reference range, yet the free concentration was usually above the reference range. The free fraction was extremely variable, making any estimate based on the total concentration highly inaccurate. Even using a published formula to predict the free fraction and free concentration showed poor agreement with the actual measured values, perhaps because this formula was derived from non-ICU patients. ${ }^{13}$ The complexity of valproate protein binding among critically ill patients this issue suggests that monitoring actual free valproate concentrations may be necessary in ICU patients.

Our study represents the largest reported cohort of ICU patients with measured free serum valproate concentrations. Our data highlight the potential benefit of monitoring free serum valproate concentrations in critically ill patients, and increase the reported cases in the ICU literature nearly five-fold. This is important because valproate is a preferred agent for seizure control and is an emerging option for the management of ICU agitation. ${ }^{8-10,19}$ A recent report suggests that valproate may be more effective $(75 \%)$ than phenytoin $(59 \%)$ or levetiracetam $(52 \%)$ to control status epilepticus. ${ }^{20}$ With recent recommendations to aggressively treat post-cardiac arrest patients with seizures and myoclonus, it is likely that valproate use will increase in this patient population. ${ }^{21}$

Several clinical factors common in the ICU are associated with higher free fractions of valproate, including uremia, hypoalbuminemia, free fatty acid administration (eg, Intralipid®, propofol, or clevidipine), and drug-drug interactions resulting in competition for albumin binding sites This article is protected by copyright. All rights reserved 
(eg, aspirin and ibuprofen). ${ }^{18,22}$ Though documented more than 30 years ago, the potential utility of monitoring free serum valproate concentrations is not mentioned in recent clinical reviews or guidelines, $^{8-10,23}$ and few ICU reports have been published. ${ }^{4-7}$ More than 10 years ago, a formula to adjust total valproate concentrations was proposed because only $2 \%$ of labs were measuring free concentrations, ${ }^{24}$ but our data suggest this formula is unreliable in ICU patients.

Older studies of outpatients treated with valproate concluded that monitoring free serum valproate concentrations was rarely helpful in patients without liver or renal disease or low albumin levels, showing free fractions in the expected range of $4-11 \% .{ }^{25,26}$ They also showed no better relationship between seizure control or adverse effects with free versus total concentration monitoring for these patients. ${ }^{25,26}$ These data may have misled clinicians who work with critically ill patients at risk for altered protein binding. Elevated free serum valproate concentrations have been associated with ataxia, nystagmus, unsteady gait, and vomiting, ${ }^{27}$ may be a stronger predictor of hyperammonemia than valproate dose or total concentration, ${ }^{28}$ and may be inversely related to platelet count. ${ }^{29}$

Valproate exhibits concentration-dependent protein binding, ${ }^{1}$ and in addition to the above factors known to alter protein binding, the normal free fraction of $5-10 \%$ may increase to $30 \%$ or higher when total concentrations exceed $72 \mathrm{mg} / \mathrm{L} .{ }^{23}$ Only one of our 15 patients had a serum total concentration greater than $72 \mathrm{mg} / \mathrm{L}$. As a low extraction ratio drug, valproate clearance is dependent on intrinsic hepatic clearance and free fraction; as free fraction increases, drug metabolism increases, potentially leading to lower than expected total serum concentrations, yet appropriate or even elevated free concentrations. ${ }^{4,11}$ This phenomenon may be even more pronounced in patients undergoing targeted temperature management because intrinsic hepatic clearance may be reduced. . $^{30,31}$

Hypoalbuminemia is a common risk factor for an increased free fraction of valproate..$^{4,6,32,33}$ The largest study published to date (including both hospitalized and outpatients) concluded that albumin values $<3.5 \mathrm{~g} / \mathrm{L}$ were associated with increased valproate free fractions, the only factor explaining therapeutic discordance between free and total serum valproate concentrations. ${ }^{33}$ All patients in our study had albumin concentrations less than $3.7 \mathrm{~g} / \mathrm{dL}$. Uremia may also alter valproate protein binding, with free fractions of $20 \%$ with renal dysfunction compared to $8 \%$ without, and a This article is protected by copyright. All rights reserved 
moderate correlation has been observed between valproate free fraction and both serum creatinine and blood urea nitrogen. ${ }^{34}$

Free fatty acids can displace highly protein bound drugs due to their high binding affinity. Stearic, palmitic, oleic, and linoleic acid have been shown to increase the free fraction of valproate in a concentration-dependent fashion by $19-118 \% .{ }^{35}$ Propofol and Intralipid® are rich in free fatty acids, and have been shown to increase the free fraction of valproate. ${ }^{36}$ Six of our patients were receiving propofol infusions. Although no patient in our study was receiving clevidipine, this dihydropyridine calcium channel blocker also contains free fatty acids and would likely increase the free fraction of valproate. Antipyretic doses of aspirin may result in a fourfold increase in valproate free fraction, and similar effects have been seen with lower salicylate doses ( $325 \mathrm{mg} /$ day $).{ }^{22,37}$ Ibuprofen can also displace valproate leading to decreasing total serum concentrations and the risk for inappropriate dose increases. ${ }^{38,39}$

Several limitations of our case series warrant comment. These data are from a single hospital, but the types of patients reported and medications co-administered are not unique to our center. We collected data from a consecutive series of patients over one year, but unexpected biases are possible. Two different total valproate reference ranges are accepted: $50-100 \mathrm{mg} / \mathrm{L}$ for seizure management and 50-125 mg/ $\mathrm{L}$ for behavioral issues. We selected the more inclusive $50-125 \mathrm{mg} / \mathrm{L}$ because some patients received valproate for behavioral issues. Though the range of $50-125 \mathrm{mg} / \mathrm{L}$ may have biased our sample toward more discordance, no patient had a total concentration $>100$ $\mathrm{mg} / \mathrm{L}$.

The data supporting specific clinical effects and adverse events associated with discrete free serum valproate concentrations are not robust, which may be the greatest limitation of our report. Indeed, $80 \%$ of the five patients without adverse events had higher values for free and total valproate concentrations. Many different reference ranges for free serum valproate concentrations have been published (eTable 1). 5,6,7,26,32,40-42 The median and interquartile range from these reports identifies a low reference value of $5 \mathrm{mg} / \mathrm{L}$ (IQR, 4.95-5 mg/L) and a high value of $12.9 \mathrm{mg} / \mathrm{L}$ (IQR, $10-15.7 \mathrm{mg} / \mathrm{L}$ ) similar to our reference range. Even if we used the highest reported range for free valproate concentrations as reported in the literature $(6-20 \mathrm{mg} / \mathrm{L})$, seven of our patients were above This article is protected by copyright. All rights reserved 
this threshold, and all were discordant (two low total concentrations, and five within the reference range of $50-100 \mathrm{mg} / \mathrm{L})$.

\section{Conclusions}

These cases highlight the great variability of valproate protein binding and free fraction among ICU patients and the potential problems associated with adjusting valproate doses based on total serum valproate concentrations. Estimating free valproate fraction or concentration by correcting for albumin level was similarly inaccurate in our ICU cohort. Monitoring free serum valproate concentrations may be appropriate for ICU patients with hypoalbuminemia, uremia, substances known to displace valproate from albumin (e.g., aspirin, ibuprofen, Intralipid®, propofol, or clevidipine), total concentrations in the high-end of the reference range (>72 mg/L), or unexpectedly low total serum valproate concentrations. Additional research to define best practice for dosing and monitoring valproate and to determine the relationship between free serum valproate concentrations and clinical and adverse effects in ICU patients is needed.

\section{Acknow ledgment:}

The authors would like to thank Zuha Bajwa, BS, from the University of New England College of Pharmacy for assistance with data collection

\section{Conflict of Interest:}

The authors declare that they have no conflict of interest.

\section{References}

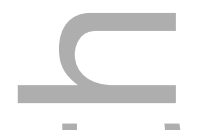

1. Patsalos PN, Berry DJ, Bourgeois BF, et al. Antiepileptic drugs--best practice guidelines for therapeutic drug monitoring: a position paper by the subcommission on therapeutic drug monitoring, ILAE Commission on Therapeutic Strategies. Epilepsia 2008;49(7):1239-1276.

2. American Psychiatric Association. Practice guideline for the treatment of patients with bipolar disorder (revision). Am J Psychiatry 2002;159:1-50.

3. Zaccara G, Messori A, Moroni F. Clinical pharmacokinetics of valproic acid - 1988. Clin Pharmcokinet 1988;15(6):367-389.

This article is protected by copyright. All rights reserved 
4. Haroldson JA, Kramer LE, Wolff DL, Lake KD. Elevated free fractions of valproic acid in a heart transplant patient with hypoalbuminemia. Ann Pharmacother 2000;34(2):183-187.

5. Lagneau F, Perbet S, Delefosse D, Wernet A, Stocco J, Marty J. Drugs pharmacokinetics in ICU patients: consequences of hypoalbuminemia upon drugs monitoring and dosing scheme Intensive Care Med 2004;30:1247.

6. de Maat MM, van Leeuwen HJ, Edelbroek PM. High unbound fraction of valproic acid in a hypoalbuminemic critically ill patient on renal replacement therapy. Ann Pharmacother 2011; 45(3):e18.

7. Jansen AJ, Hunfeld NG, van Bommel J, Koch BC, van Gelder T. Therapeutic drug monitoring of free fraction valproic acid in patients with hypoalbuminaemia. Neth J Med 2012;70(7):329.

8. Claassen J, Riviello JJ, Silbergleit R. Emergency Neurological Life Support: Status Epilepticus. Neurocrit Care 2015;23:S136-S142.

9. Brophy GM, Bell R, Claassen J, et al. Guidelines for the evaluation and management of status epilepticus. Neurocrit Care 2012;17:3-23.

10. Trinka E, Höfler J, Zerbs A, Brigo F. Efficacy and safety of intravenous valproate for status epilepticus: a systematic review. CNS Drugs 2014;28:623-639.

11. Haymond J, Ensom MH. Does Valproic Acid Warrant Therapeutic Drug Monitoring in Bipolar Affective Disorder? Ther Drug Monit 2010;32:19-29.

12. Hiemke C, Baumann P, Bergemann N, et al. AGNP Consensus Guidelines for Therapeutic Drug Monitoring in Psychiatry: Update 2011. Pharmacopsychiatry 2011;44(6):195-235.

13. Parent X, Marzullo C, Gutbub AM. Acide valproïque: estimation simple de la concentration sérique libre. Ann Biol Clin (Paris) 1993;51:649-650.

14. Lampon N, Tutor JC. Apparent clearance of valproic acid in elderly epileptic patients: estimation of the confounding effect of albumin concentration. Upsala Journal of Medical Sciences 2012;117: $41-46$.

15. Navarro VJ, Senior JR. Drug-related hepatotoxicity. N Engl J Med 2006;354(7):731-739.

16. Wazny LD, Ariano RE. Evaluation and management of drug-induced thrombocytopenia in the acutely ill patient. Pharmacotherapy 2000;20(3):292-307.

17. Bland JM, Altman DG. Statistical methods for assessing agreement between two methods of clinical measurement. Lancet 1986;327 (8476): 307-310.

18. Levy RH. Monitoring of free valproic acid levels? Ther Drug Monit 1980;2(2):199-201.

This article is protected by copyright. All rights reserved 
19. Gagnon DJ, Fontaine GV, Smith KE, et al. Valproate for agitation in critically ill patients: a retrospective study. J Crit Care 2016;37:119-125.

20. Alvarez V, Januel JM, Burnand B, Rossetti AO. Second line status epilepticus treatment: comparison of phenytoin, valproate, and levetiracetam. Epilepsia 2011;52(7):1292-1296.

21. Monsieurs KG, Nolan JP, Bossaerte LL, et al. European Resuscitation Council Guidelines for Resuscitation 2015 Section 1. Executive summary. Resuscitation 2015;95:1-80.

22. Orr JM, Abbott FS, Farrell K, Ferguson S, Sheppard I, Godolphin W. Interaction between valproic acid and aspirin in epileptic children: serum protein binding and metabolic effects. Clin Pharmacol Ther 1982;31:642-649.

23. Bowdle AT, Patel IH, Levy RH, Wilensky AJ. Valproic acid dosage and plasma protein binding and clearance. Clin Pharmacol Ther 1980;28(4):486-492.

24. Hermida J, Tutor JC. A theoretical method for normalizing total serum valproic acid concentration in hypoalbuminemic patients. J Pharmacol Sci 2005;97:489-493.

25. Kilpatrick $\mathrm{C}$, Bury RW, Fullinfaw RO, et al. Plasma concentrations of unbound valproate and the management of epilepsy. Aust N Z J Med 1987;17(6):574-579.

26. Froscher W, Burr W, Penin H, Vohl J, Bülau P, Kreiten K. Free level monitoring of carbamazepine and valproic acid: clinical significance. Clin Neuropharmacol 1985;8:362-371.

27. Chan K, Beran RG. Value of therapeutic drug level monitoring and unbound (free) levels. Seizure 2008;17(6):572-575.

28. Itoh H, Suzuki Y, Fujisaki K, Sato Y, Takeyama M. Correlation between plasma ammonia level and serum trough concentration of free valproic acid in patients with epilepsy. Biol Pharm Bull 2012;35(6):971-974.

29. Gidal B, Spencer N, Maly M, et al. Valproate-mediated disturbances of hemostasis: relationship to dose and plasma concentration. Neurology 1994;44(8):1418-1422.

30. Šunjić KM, Webb AC, Šunjić I, Palà Creus M, Folse SL. Pharmacokinetic and other considerations for drug therapy during targeted temperature management. Crit Care Med 2015;43:2228-2238.

31. Riker RR, Gagnon DJ, May T, Seder DB, Fraser GL. Analgesia, sedation, and neuromuscular blockade during targeted temperature management after cardiac arrest. Best Pract Res Clin Anaesthesiol 2015;29 (4):435-450.

32. Levy RH, Moreland TA. Rationale for monitoring free drug levels. Clin Pharmacokinet 1984;9 Suppl $1: 1-9$.

This article is protected by copyright. All rights reserved 
33. Gibbs HG, Zimmerman DE, Shermock KM, Clarke W, Mirski MA, Lewin JJ 3rd. Comparison of free fraction serum valproic acid concentrations between inpatients and outpatients. Am J Health Syst Pharm 2015;72(2):121-126.

34. Gugler R, Mueller G. Plasma protein binding of valproic acid in healthy subjects and in patients with renal disease. Br J Clin Pharmacol 1978;5(5):441-446.

35. Patel IH, Levy RH. Valproic acid binding to human serum albumin and determination of free fraction in the presence of anticonvulsants and free fatty acids. Epilepsia 1979;20(1):85-90.

36. Zimmerman CL, Patel IH, Levy RH, Edwards D, Nelson SD, Hutchinson M. Protein binding of valproic acid in the presence of elevated free fatty acids in patient and normal human serum. Epilepsia 1981;22(1):11-17.

37. Sandson NB, Marcucci C, Bourke DL, Smith-Lamacchia R. An interaction between aspirin and valproate: the relevance of plasma protein displacement drug-drug interactions. Am J Psychiatry 2006;163(11):1891-6.

38. Lana F, Martí-Bonany J, de Leon J. Ibuprofen May Increase Pharmacological Action of Valproate by Displacing It From Plasma Proteins: A Case Report. Am J Psychiatry 2016;173(9):941-2.

39. Lana F, Marti-Bonany J, Fuster J, de Leon J. Reduction in serum concentration of valproic acid secondary to the intake of ibuprofen as an example of valproic acid auto-induction metabolism. Actas Esp Psiquiatr 2016;44:136-144.

40. Beran RG, Lewis JH, Nolte JL, Westwood AP. Use of total and free anticonvulsant serum levels in clinical practice. Clin Exp Neurol 1985;21:69-77.

41. Mayerhoff DI, Nurenberg J, Shah S, Schleifer SJ. Neurotoxicity associated with free valproic acid. Am J Psychiatry 2005;162(4):810.

42. Xiong GL, Ferranti J, Leamon MH. Toxic interaction between valproate and oxcarbazepine: a case detected by the free valproate level. J Clin Psychopharmacol 2008;28(4):472-473.

\section{Tables}

Table 1: Patient demographics and clinical outcomes

\begin{tabular}{|l|c|}
\hline \multicolumn{2}{|c|}{ Demographics } \\
\hline Age, years & $63(29-72)$ \\
\hline Male, N (\%) & $9(60 \%)$ \\
\hline Ethnicity, Caucasian & $14(93 \%)$ \\
\hline
\end{tabular}

This article is protected by copyright. All rights reserved 


\begin{tabular}{|c|c|}
\hline \multicolumn{2}{|l|}{ ICU admitting diagnosis } \\
\hline Cardiac Arrest & $5(33 \%)$ \\
\hline Seizures & $4(27 \%)$ \\
\hline Acute respiratory failure & $4(27 \%)$ \\
\hline Sepsis & $1(7 \%)$ \\
\hline HSV encephalitis & $1(7 \%)$ \\
\hline Weight, kg median (IQR) & $95(73-109)$ \\
\hline \multicolumn{2}{|c|}{ Outcomes } \\
\hline ICU mortality & $3(20 \%)$ \\
\hline Hospital mortality & $6(40 \%)$ \\
\hline \multicolumn{2}{|l|}{ Discharge disposition } \\
\hline Deceased & $6(40 \%)$ \\
\hline Rehabilitation & $4(27 \%)$ \\
\hline Home & $3(20 \%)$ \\
\hline Transfer & $2(13 \%)$ \\
\hline ICU length of stay, days median (IQR) & $11(8-27)$ \\
\hline Hospital length of stay, days & $21(10-34)$ \\
\hline
\end{tabular}

Continuous variables reported as median (IQR), nominal variables as frequency $n(\%)$

Table 2: Our $15 \mathrm{ICU}$ cases of free valproate monitoring and 4 previously reported cases

\begin{tabular}{|c|c|c|c|c|c|c|c|c|c|c|c|}
\hline Case & $\begin{array}{c}\text { Age } \\
\text { years }\end{array}$ & Gender & $\begin{array}{c}\text { Dose } \\
\text { grams }\end{array}$ & $\begin{array}{c}\text { Albumin } \\
\text { g/dL }\end{array}$ & $\begin{array}{c}\text { BUN } \\
\mathrm{mg} / \mathrm{dL}\end{array}$ & $\begin{array}{c}\text { Creat } \\
\mathrm{mg} / \mathrm{dL}\end{array}$ & Drugs & $\begin{array}{c}\text { Total } \\
\text { Valproate } \\
\mathrm{mg} / \mathrm{L}\end{array}$ & $\begin{array}{c}\text { Free } \\
\text { Valproate } \\
\mathrm{mg} / \mathrm{L}\end{array}$ & $\begin{array}{c}\text { Free } \\
\text { Fraction }\end{array}$ & $\begin{array}{c}\text { Adverse } \\
\text { Events }\end{array}$ \\
\hline $\mathbf{1}$ & 72 & $\mathrm{M}$ & 6 & 2.2 & 27 & 0.87 & $\mathrm{PS}$ & 22.2 & 19 & 0.86 & A, H, D \\
\hline $\mathbf{2}$ & 62 & $\mathrm{M}$ & 4 & 2 & 49 & 1.14 & - & 53 & 20 & 0.38 & A,D \\
\hline
\end{tabular}

This article is protected by copyright. All rights reserved 


\begin{tabular}{|c|c|c|c|c|c|c|c|c|c|c|c|}
\hline 3 & 93 & $F$ & 3 & 2.4 & 27 & 1.06 & $\mathbf{P}$ & 71 & 37 & 0.52 & - \\
\hline 4 & 69 & $\mathrm{M}$ & 2 & 2.7 & 8 & 0.56 & - & 53 & 32 & 0.6 & $=$ \\
\hline 5 & 19 & $\mathrm{~F}$ & 4 & 3 & 9 & 0.32 & - & 42 & 18 & 0.43 & A \\
\hline 6 & 72 & $F$ & 1 & 2.1 & 57 & 3.3 & $S$ & 52.1 & 18 & 0.35 & $A, T$ \\
\hline 7 & 26 & M & 3 & 2.4 & 18 & 0.57 & $\mathbf{P}$ & 29.1 & 26 & 0.89 & $A, T$ \\
\hline 8 & 69 & $\mathrm{M}$ & 3 & 2.4 & 33 & 1.21 & - & 65 & 31 & 0.48 & - \\
\hline 9 & 67 & 1 & 2 & 3.2 & 26 & 5.6 & - & 23 & 19 & 0.83 & - \\
\hline 10 & 81 & $\bar{M}$ & 2.25 & 2.2 & 8 & 0.57 & $P$ & 73 & 11 & 0.15 & $T$ \\
\hline 11 & 51 & $F$ & 3.6 & 2.7 & 12 & 0.41 & - & 47 & 22 & 0.47 & A \\
\hline 12 & 24 & & 4 & 2.9 & 29 & 4.3 & $\mathbf{P}$ & 27 & 13 & 0.48 & $\mathrm{H}, \mathrm{T}$ \\
\hline 13 & 29 & $F$ & 1 & 3.7 & 19 & 0.95 & - & 51 & 12 & 0.24 & A \\
\hline 14 & 63 & & 4.5 & 3 & 19 & 0.49 & $S$ & 56 & 29 & 0.52 & - \\
\hline 15 & 40 & $M$ & 3 & 2.2 & 21 & 0.57 & $\mathbf{P}$ & 92 & 37 & 0.4 & $T$ \\
\hline $\begin{array}{c}\text { Median } \\
\text { (IQR) or } \\
\mathrm{N}(\%)\end{array}$ & $\begin{array}{c}63(34- \\
70)\end{array}$ & & $3(2-4)$ & $\begin{array}{c}2.4(2.2- \\
3.0)\end{array}$ & $\begin{array}{r}21 \\
(15- \\
28)\end{array}$ & $\begin{array}{r}0.87 \\
(0.56- \\
1.2)\end{array}$ & $\begin{array}{c}6 \mathrm{P} \\
(40 \%) \\
3 \mathrm{~S} \\
(20 \%)\end{array}$ & $52(29-65)$ & $20(18-30)$ & $\begin{array}{r}0.48 \\
(0.39- \\
0.56)\end{array}$ & $\begin{array}{c}7 \mathrm{~A}, 2 \mathrm{H}, 5 \\
\mathrm{~T}, 2 \mathrm{D}\end{array}$ \\
\hline Ref 4 & 52 & & 3.5 & 1.6 & * & * & * & 46 & 35 & 0.76 & T,D \\
\hline Ref 5 & 29 & $+*$ & * & 0.8 & * & * & - & 14 & 13 & 0.93 & D \\
\hline Ref 6 & 61 & $\mathrm{~F}$ & 0.9 & 1.2 & * & * & - & 15.5 & 9.3 & 0.60 & D \\
\hline Ref 7 & 53 & $M$ & 2.4 & 2.1 & * & * & * & 62 & 17 & 0.27 & $\mathbf{A}$ \\
\hline
\end{tabular}

Data are presented as incidence $(\%)$ and median (interquartile range). Drugs $=$ medications that alter valproate protein binding $-\mathrm{P}=$ Propofol, $\mathrm{S}=$ Salicylate; $\mathrm{M}=$ Male, $\mathrm{F}=$ Female; $\mathrm{A}=$ Ammonia elevation, $\mathrm{H}=$ hepatic dysfunction, $\mathrm{T}=$ Thrombocytopenia, $\mathrm{D}=$ Drug Dosing error, ${ }^{*}=$ data not reported

\section{Figure Legends}

Fig 1 Index Case data showing decreasing total serum valproate concentrations (squares) despite repeated dose increases (vertical bars), and a free fraction on day 14 of $86 \%$ (free concentration 19 $\mathrm{mg} / \mathrm{L}$ - large triangle, total concentration $22 \mathrm{mg} / \mathrm{L}$ ).

Fig 2 Simultaneous free and total valproate concentrations. The diagonal up to right shading reflects This article is protected by copyright. All rights reserved 
the reference range for the free concentration on the $Y$ axis $(5-17 \mathrm{mg} / \mathrm{L})$, the diagonal up to the left shading reflects the reference range for the total concentration on the $X$ axis $(50-125 \mathrm{mg} / \mathrm{L})$, the solid grey rectangle reflects the concordance of the these two reference ranges. Triangles represent patients without adverse events. Diamonds represent patients with adverse events, two of which were therapeutically concordant (both in reference range with unfilled diamonds), the remaining 13 symbols are solid diamonds or triangles reflecting therapeutically discordant values.

a

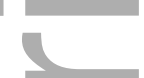

Fig 3 Free versus estimated-free serum valproate concentration calculated from albumin using Parent formula. Diagonal line = Line of Identity. The Parent formula underestimated free valproate concentrations $(r=0.45)$

Figure 1

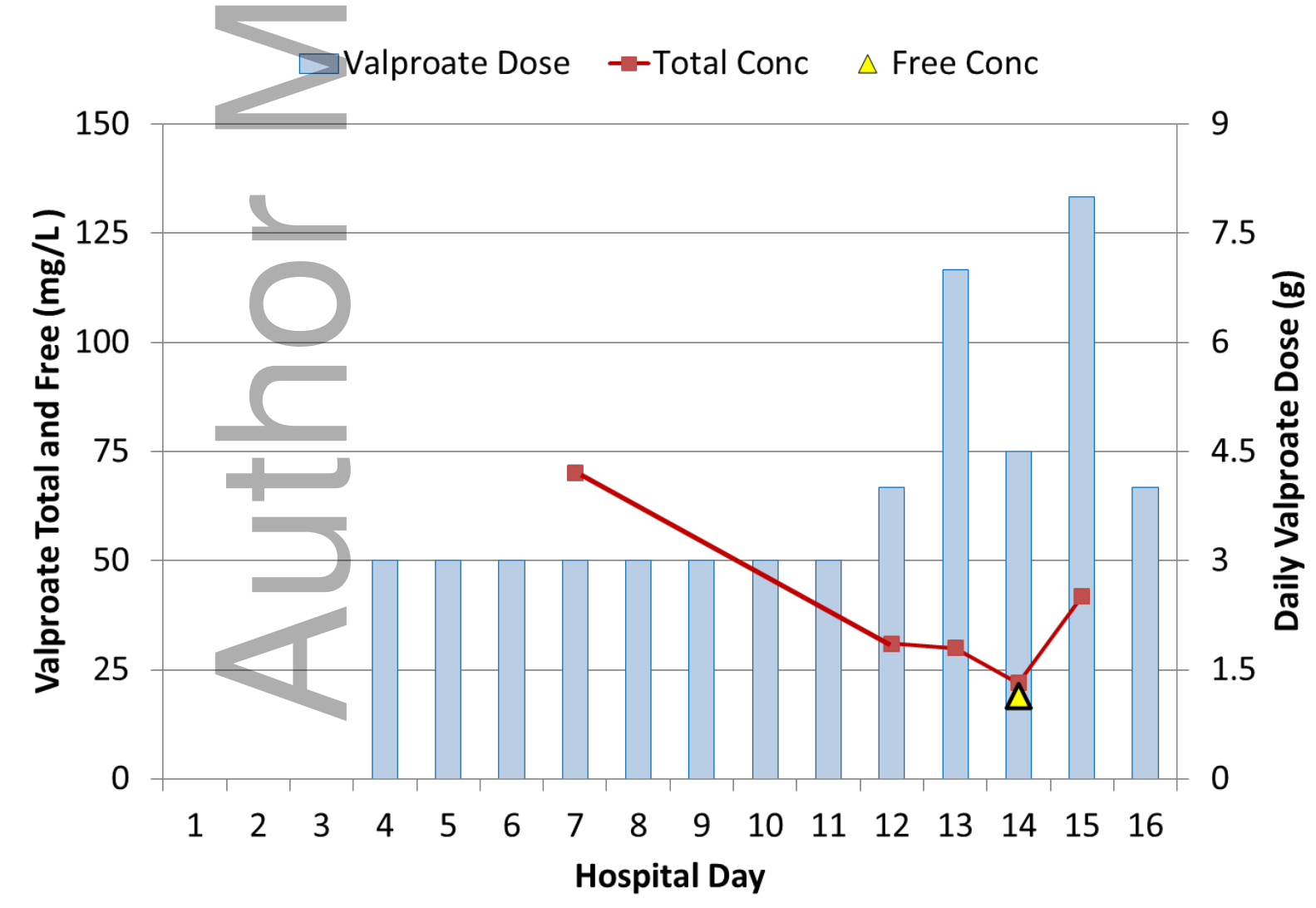

This article is protected by copyright. All rights reserved 
Figure 2
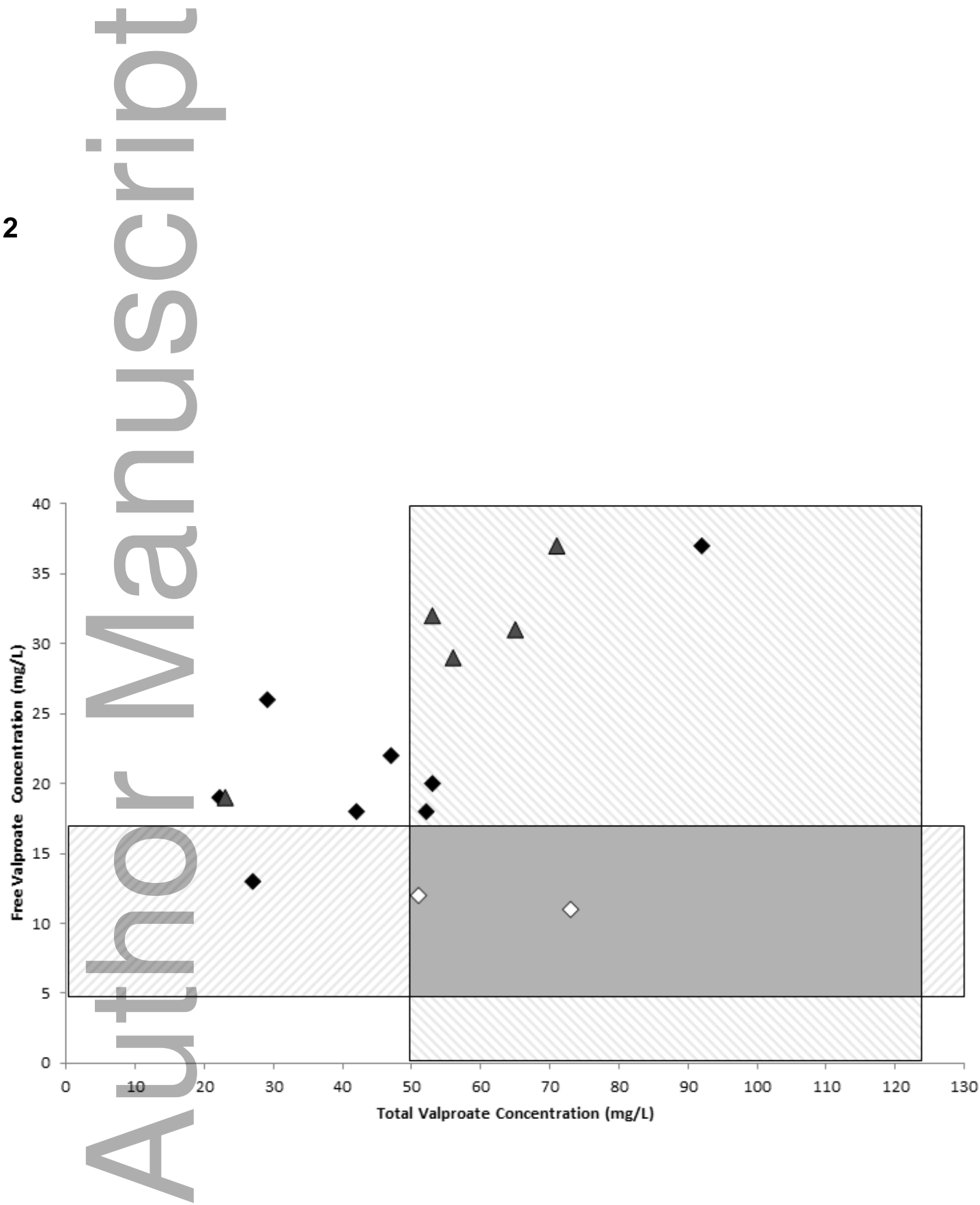

Figure 3

This article is protected by copyright. All rights reserved 


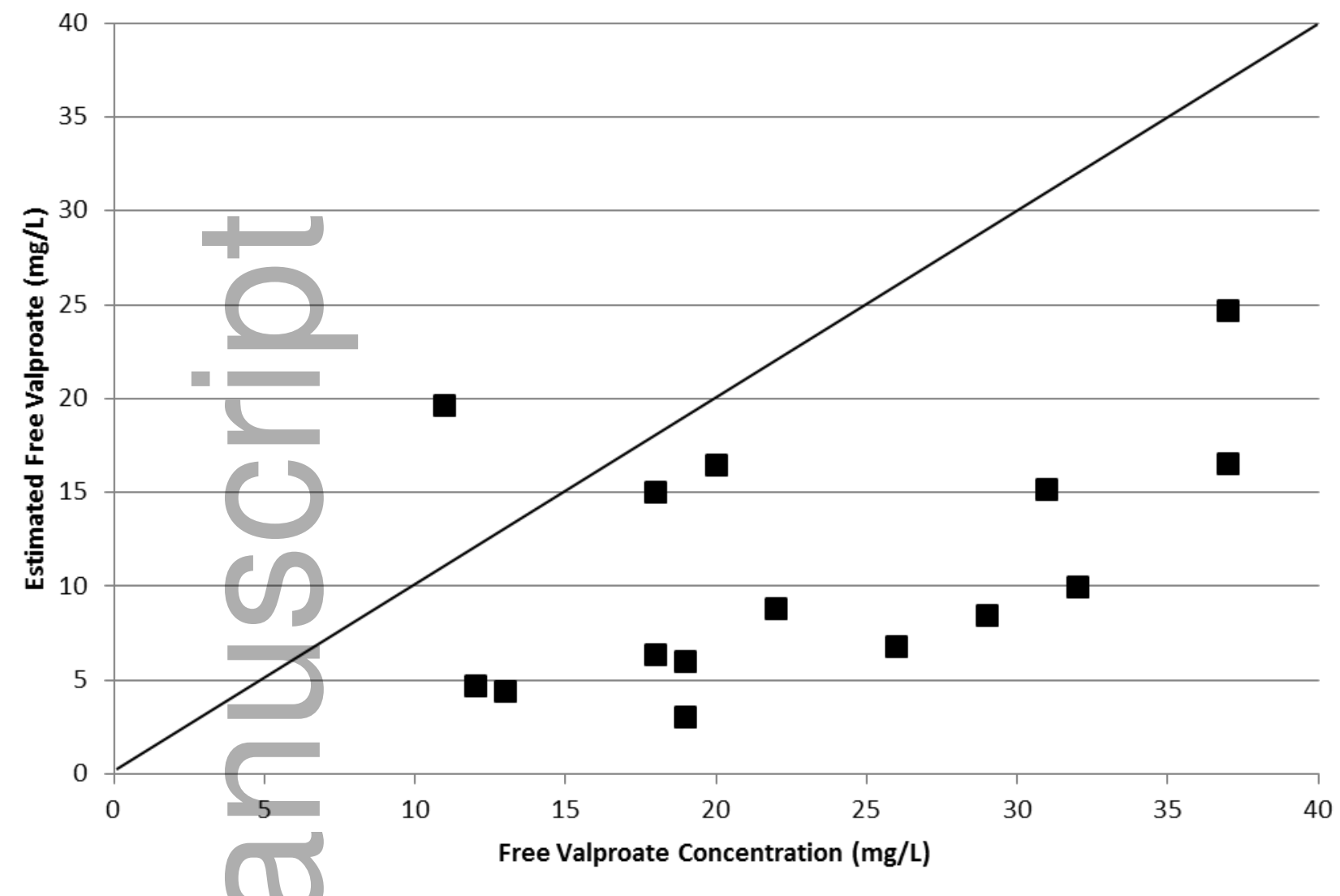

This article is protected by copyright. All rights reserved 


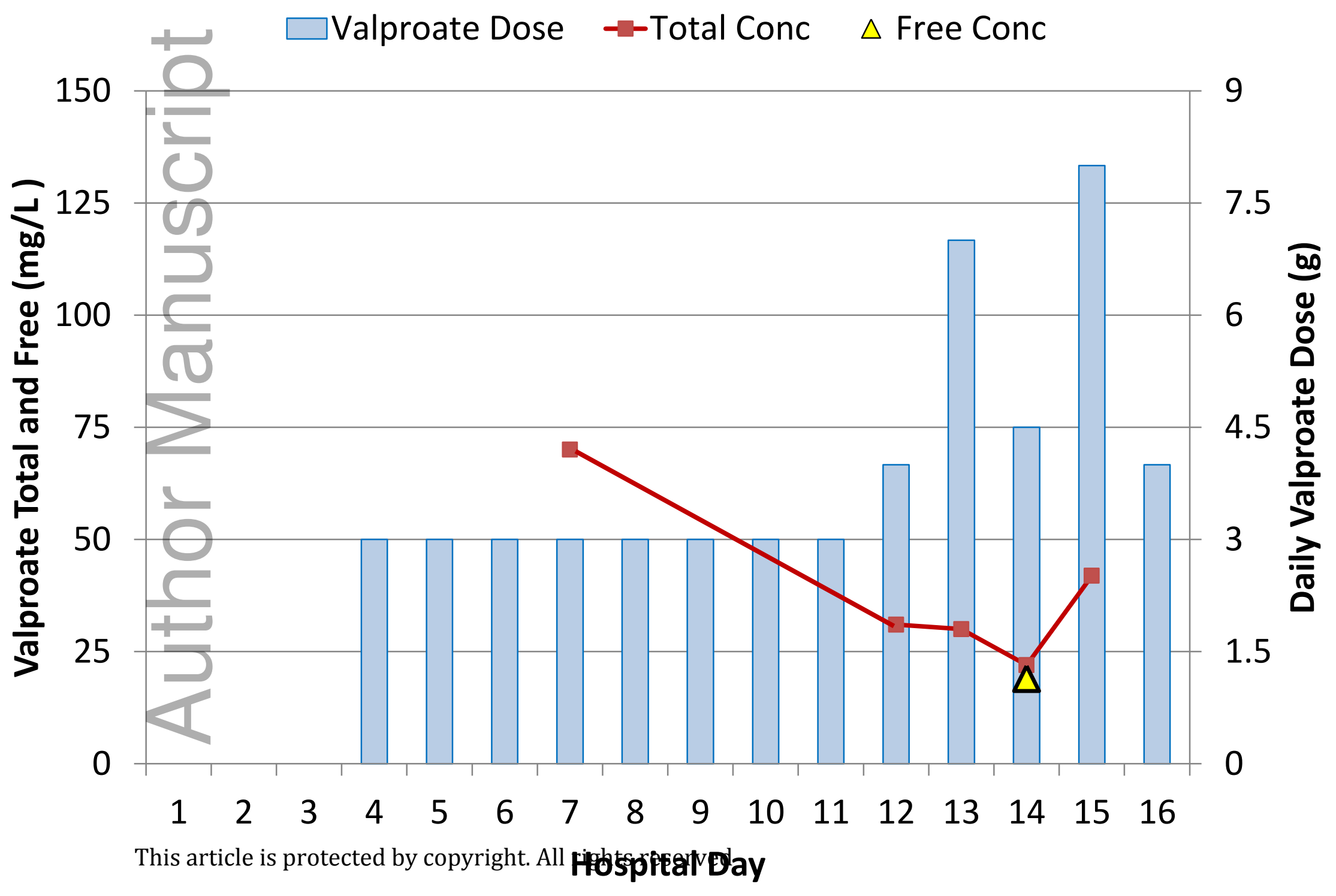




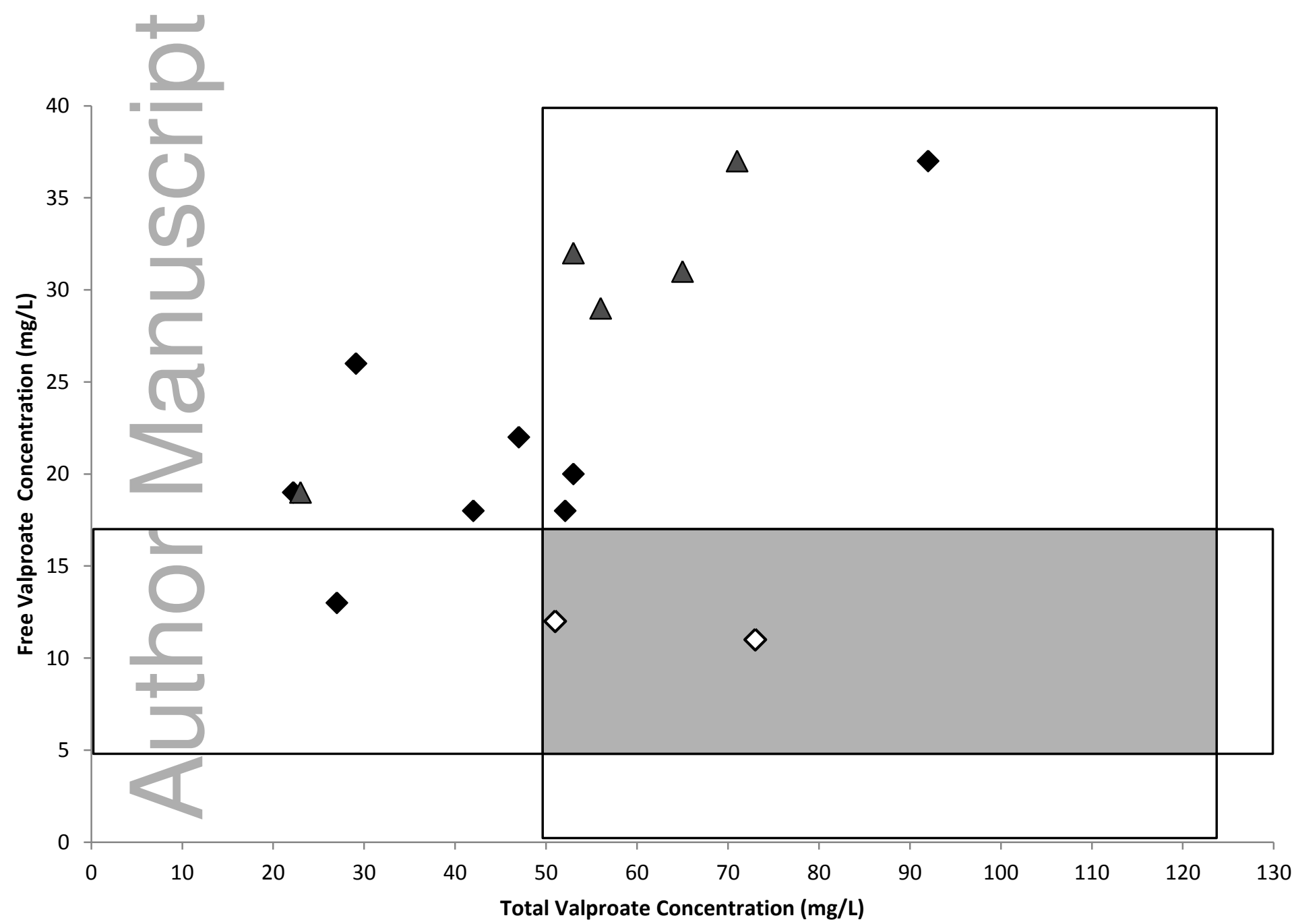

This article is protected by copyright. All rights reserved 

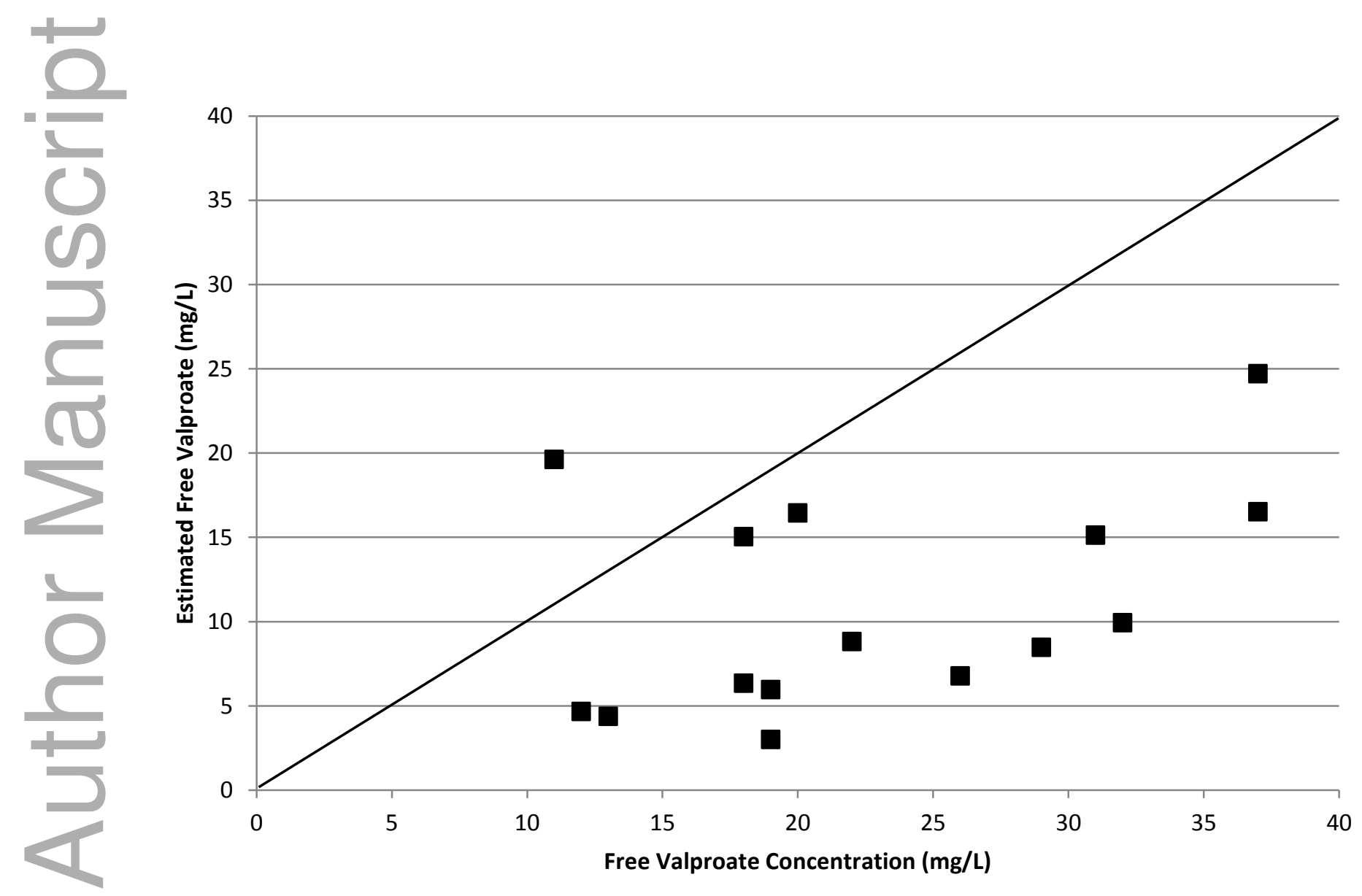

This article is protected by copyright. All rights reserved 